https://helda.helsinki.fi

Current and recalled childhood gender identity in community youth in comparison to referred adolescents seeking sex reassignment

Sumia, Maria

2017-04

Sumia , M , Lindberg , N , Tyolajarvi , M \& Kaltiala-Heino , R 2017 , ' Current and recalled childhood gender identity in community youth in comparison to referred adolescents seeking sex reassignment ' , Journal of Adolescence , vol. 56 , pp. 34-39 . https://doi.org/10.1016/j.adolescence.2017.01.006

http://hdl.handle.net/10138/236703

https://doi.org/10.1016/j.adolescence.2017.01.006

publishedVersion

Downloaded from Helda, University of Helsinki institutional repository.

This is an electronic reprint of the original article.

This reprint may differ from the original in pagination and typographic detail.

Please cite the original version. 
Brief report

\title{
Current and recalled childhood gender identity in community youth in comparison to referred adolescents seeking sex reassignment
}

\author{
Maria Sumia ${ }^{a}$, Nina Lindberg ${ }^{b}$, Marja Työläjärvi a , Riittakerttu Kaltiala- \\ Heino ${ }^{\text {a, c, d, * }}$ \\ a Tampere University Hospital, Department of Adolescent Psychiatry, Box 2000, 33521, Tampere, Finland \\ ${ }^{\mathrm{b}}$ Helsinki University and Helsinki University Hospital, Forensic Psychiatry, Kellokoski Hospital, 04500, Kellokoski, Finland \\ ${ }^{c}$ University of Tampere, School of Medicine, 33014, University of Tampere, Finland \\ ${ }^{\mathrm{d}}$ Vanha Vaasa Hospital, Vierinkiventie 1, 65380, Vaasa, Finland
}

\section{A R T I C L E I N F O}

\section{Article history:}

Received 25 January 2016

Received in revised form 13 January 2017

Accepted 18 January 2017

Available online 28 January 2017

\section{Keywords:}

Gender identity

Gender dysphoria

Adolescence

\begin{abstract}
A B S T R A C T
We studied current (GIDYQ-A) and recalled (RCGI) childhood gender identity among 719 upper secondary school students 401 girls, mean age $17.0(S D=0.88)$ years old and 318 boys, mean age 17.2 ( $S D=0.86$ years old in Finland. We also compared these dimensions of identity in community youth to same dimensions among adolescent sex reassignment (SR) applicants. Most community youth scored high on the normative, cis-gender end of gender experience (median score 4.9 for boys and 4.9 for girls) and recalled fairly gender typical childhood behaviours and experiences. The girls displayed more gender non-conformity in childhood. Among the boys $2.2 \%$ and among the girls $0.5 \%$ displayed potentially clinically significant gender dysphoria on the GIDYQ-A. The community youth differed clearly from adolescent SR applicants on current and recalled childhood gender identity (SR applicants were 47,6 natal boys and 41 natal girls, average ages were 16.4 years old $(S D=0.93)$ and girls were on average 16.8 years old $(S D=1.0)$.

(C) 2017 The Foundation for Professionals in Services for Adolescents. Published by Elsevier
\end{abstract} Ltd. All rights reserved.

Gender Dysphoria (DSM-5; American Psychiatric Association, 2013) or transsexualism (ICD-10; World Health Organization, 1992) refers to a marked difference between a person's experienced gender and biological sex with a desire to live as a member of the opposite sex, and often a desire for hormonal and surgical treatment to make the body congruent with the preferred sex. Gender dysphoria also refers to overall anxiety and distress about sexual characteristics, while gender variance refers an experience of gender contrary to that of one's biological sex.

Treatment-seeking figures suggest a prevalence of transsexualism of 6.8/100,000 for male to female (MtF) and 2.6/100,000 for female to male (FtM; Arcelus et al., 2015). Gender dysphoria/transgender identification may be more common in general population. In the Netherlands $0.6 \%$ of men and $0.2 \%$ of women (aged $15-70$ years old) reported incongruent gender identity and a desire to undergo sex reassignment (SR; Kuyper \& Wijsen, 2014). Connolly, Zervos, Barone, Johnson, and Joseph (2016) in their review concluded that among community adolescents $0.17-1.3 \%$ identify as transgender. Among children, the

\footnotetext{
* Correspoding author. Tampere University Hospital, Department of Adolescent Psychiatry, Box 2000, 33521, Tampere, Finland.

E-mail address: merihe@uta.fi (R. Kaltiala-Heino).
} 
prevalence of gender dysphoria/variance has not been reliably estimated (Costa, Carmichael, \& Colizzi, 2016; Olson-Kennedy et al., 2016).

Adolescents in Europe and North America are increasingly seeking SR (Kaltiala-Heino, Sumia, Työläjärvi, \& Lindberg, 2015; Meyenburg, 2014; Meyenburg, Korte, Moller, \& Romer, 2014; Wood et al., 2013). FtM applicants predominate in referrals (Aitken et al., 2015; Kaltiala-Heino et al., 2015; Meyenburg, 2014; Wood et al., 2013). Studies on the prevalence of gender dysphoria/variance in adolescence are scarce, and gender identity has mainly been studied using single questions (Connolly et al., 2016). The prevalence is moreover likely to vary between countries (Costa et al., 2016), and is unknown in Finland. Our aim was to examine current and recalled childhood gender dysphoria/variation among community youth. Specifically, we sought answers to the following questions:

1. Do community girls and boys display variation in current and recalled gender identity, and does the possible variation form a continuum that in the non-conforming end merges with experiences of adolescent SR applicants?

2. What proportions of boys and girls in the community display potentially clinically significant gender dysphoria/variation?

3. Is the recalled childhood gender identity among those adolescents who reveal potentially clinically significant gender dysphoria/variation more reminiscent of that in other community youth or that in adolescent SR applicants?

Given the increase in numbers of adolescent SR applicants, we hypothesized a continuum of gender variation in the community. As effeminate self-expression in boys is less condoned than masculine self-expression in girls (Ristori \& Steensma, 2016) and FtM applicants dominate in referrals, we hypothesized that both recalled childhood and current gender identity would be more non-conformant among girls, and that the proportion of community youth displaying potentially clinically significant gender dysphoria would be greater in girls. We expected that the childhood gender identity of those community youth currently scoring within the potentially clinical range would fall in between that in SR applicants and others in the community, nevertheless reflecting milder gender dysphoria than that seen in treatment seekers.

\section{Method}

\subsection{Participants}

Students in three upper secondary schools in Tampere, Finland (population 230,000) were recruited during the academic year 2012-2013 to respond anonymously to a classroom questionnaire on current and childhood gender experience. They were informed about the voluntary nature of participation and their option to return an empty form. To ensure anonymity, returning a completed questionnaire was taken as consent to participate. The study was approved by the Helsinki University Hospital Ethics Committee and the Tampere school administration. Community participants were 401 girls aged on average 17 years old $(S D=0.88)$ and 318 boys on average aged 17.2 years old $(S D=0.86)$. Unfortunately, the number of those not attending class when the surveys were distributed is not known. All the forms distributed were filled in.

The community participants were compared to adolescent SR applicants $(n=47)$ assessed in one of the two gender identity teams for minors in Finland in 2011-2013 (Kaltiala-Heino et al., 2015). The surveys used in this study are routinely used when interviewing adolescent SR applicants. The data were collected retrospectively from case files. The clinical study was approved by the ethics committee of Tampere University Hospital. The 47 SR applicants were six natal boys, mean age 16.4 years old $(S D=0.93)$ and 41 natal girls average age 16.8 years old $(S D=1.0)$.

\subsection{Measures}

Current gender identity was assessed with the Gender Identity/Gender Dysphoria Questionnaire for adolescents (GIDYQA; Deogracias et al., 2007). The GIDYQ-A includes 27 items on gender identity/dysphoria during the past 12 months. Each item is rated on a 5-point scale and the mean of all items forms a GIDYQ-A total score ranging from one to five. Scores $<3.0$ suggest clinically significant gender dysphoria. GIDYQ-A distribution was skewed and Cronbach's alpha in the combined clinical and population sample was .90 .

The Recalled Childhood Gender Identity scale (RCGI) is a 23-item questionnaire on gender gender experience/behaviour in childhood (Zucker et al., 2006). The items have 5-point response option. Four subscales measure typically feminine or masculine behaviours/preferences and conforming/not conforming to gender roles, and five items measure the parent-child relationship. The items are coded so that for boys(girls), higher scores indicate more marked masculine (feminine) behaviours and preferences, feeling good about being a boy (girl), and closeness to father(mother). The RCGI subscales were normally distributed and Cronbach's alphas for the subscales in this sample were: female-typical 0.95, male-typical 0.85, lowconforming 0.45 , low-nonconforming 0.68 .

\subsection{Data analyses}

To explore variation in current gender identity among the community youth, their GIDYQ-A item responses, GIDYQ-A total scores interquartile ranges (IQR) and medians are presented for girls and boys. The GIDYQ-A IQRs of community girls and boys 
were compared to those displayed by FtM and MtF applicants, respectively. Mann-Whitney U-test comparisons of the total scores were carried out between community girls and boys, and between community girls (boys) and FtM (MtF) applicants, and medians are presented.

To explore variation in recalled childhood gender identity RCGI subscale scores were used. RCGI means (sd) were compared with between groups t-tests. Community girls and boys, community girls (boys) and FtM (MtF) applicants were compared in order to identify gender differences within the community sample and between community youth and SR applicants. IQRs are presented. Due to multiple comparison $(3 \times 4)$, Bonferroni correction was applied, setting statistical significance at $\mathrm{p}<.004(0.05 / 12)$.

The proportion (\%, 95\% confidence intervals) of those displaying clinically significant gender dysphoria in the community sample (GIDYQ-A score < 3.0) was calculated.

The RCGI-subscale means of those community youth who displayed potentially clinically significant gender dysphoria/ variation were compared with those of other community youth and those of SR applicants of the same natal sex using $t$-test. Due to multiple comparison $(3 \times 4)$, Bonferroni correction were applied, setting statistical significance at $p<.004(.05 / 12)$.

Spearman's correlation coefficients were calculated to analyse whether age was important to the non-normally distributed GIDYQ-A scores, and Pearson's correlation coefficients similarly for the normally distributed RCGI subscales. As age was not found to not be important in these analyses, it was excluded from further analyses.

\section{Results}

In most of the GIDYQ-A items, nine out of ten community girls and boys reported experiences at the normative, cis-gender end (always/often or never/rarely) (See Table 1). GIDYQ-A IQR was 4.8-5.0 for boys and 4.7-5.0 for girls. GIDYQ-A total score median was 4.9 for both boys and girls ( $\mathrm{p}=\mathrm{ns}$ ). GIDYQ-A IQR was 2.0-2.6 for MtF and 1.9-2.3 for FtM applicants. The GIDYQA total score median was 2.2 among the MtF and 2.1 among FtM applicants; the medians differed from those in the community youth at level $p<.001$.

Community boys recalled more male-typical and girls more female-typical childhood behaviours and preferences, but girls presented as deviating more from gender roles in childhood than did boys, and IQRs suggested partially overlapping variation (See Table 2). Community girls (boys) indicated statistically significantly more conformance with female (male) role on three (all) of the RCGI subscales than did FtM (MtF) applicants (See Table 2). Of the community boys, $2.2 \%$ (95\% CI 0.6\%$3.8 \%$ ), and of the girls, $0.5 \%(-0.2 \%-1.2 \%)$ scored $<3$ on GIDYQ-A ( $p=0.04$ ) (of all, $1.3 \%$ (95\% CI $0.5 \%-2.1 \%$ ).

Community boys scoring $<3$ on GIDYQ-A recalled fewer male-typical childhood behaviours than did other boys (mean (sd) 9.1(3.8) vs. 12.5(2.5), $p<.001$ ). Community girls scoring $<3$ on GIDYQ-A reported more non-conformity than other girls on the scale where low values indicate non-conformity (mean(sd) 8.0(1.4) vs. 13-5(2.1), $p<.001$ ). Community girls(boys) scoring $<3$ on GIDYQ-A did not differ statistically significantly from the FtM (MtF) applicants on the RCGI subscales.

\section{Discussion}

There was little current gender variation in the community youth according to GIDYQ-A. The responses of both girls and boys accumulated at the normative, cis-gender end of GIDYQ-A, and differed clearly from experiences reported by SR applicants. The hypothesized continuum of current gender variation in community youth was not confirmed.

Community girls and boys recalled childhood gender identities typical of their natal sex, and, predictably, greater gender conformity than SR applicants of their natal sex. Hypothesized continuum of variation received support. Community girls reported more gender non-conformity than boys. This lends support to our hypothesis concerning sex difference in recalled childhood gender identity. Finland ranks high in gender equality (Eige, n.d.; Tilastokeskus, 2016). Thus, gender roles may be less dichotomized than elsewhere, possibly allowing female children more room to express themselves freely in regards to behaviours considered gender-atypical. Masculinity in girls may further be increasingly accepted, in contrast to femininity in boys (Ristori \& Steensma, 2016). Whether this is related to FtM overrepresentation in adolescent SR applicants (KaltialaHeino et al., 2015) is not known.

That $1.3 \%$ of community youth scored within the clinical range in GIDYQ-A corresponds to earlier prevalence figures based on a single question about transgender identification among adolescents (Connolly et al., 2016). This prevalence is high compared to estimates based on treatment-seeking (Arcelus et al., 2015), and higher than that found in population surveys among adults (Kuyper \& Wijsen, 2014) and young adults (Diemer, Grant, Munn-Chernoff, Patterson, \& Duncan, 2015), possibly suggesting that in younger cohorts gender dysphoria is more prevalent. This is important information for the planning of health education and health services. More boys' than girls' scores indicated clinical gender dysphoria. This corroborates the larger number of MtF SR applicants on average (Arcelus et al., 2015), but study result is disparate with findings that indicate that adolescent FtM applicants vastly (>8:1) outnumber MtF applicants in Finland (Kaltiala-Heino et al., 2015).

Community youth with scores indicative of clinical current gender dysphoria did not differ from SR applicants of their natal sex regarding recalled childhood gender identity. Contrary to our hypothesis, this suggests that they may clinically resemble those seeking treatment.

In adolescence, identity is established through identity processes, exploration and commitment making (Kroger, Martinussen, \& Marcia, 2010; Luyckx, Teppers, Klimstra, \& Rassart, 2014; Moshman, 2011). GIDYQ-A and RCGI, although 
Table 1

Distribution (\%) of Gender Identity/Gender Dysphoria Questionnaire (GIDY-A) item responses among 16-19-year-old boys ( $\mathrm{n}=381)$ and girls ( $\mathrm{n}=401)$ in the community.

\begin{tabular}{|c|c|c|c|c|c|c|}
\hline GIDYQ-A item & Always & Often & Some-times & Rarely & Never & Missing \\
\hline \multicolumn{7}{|c|}{ Satisfied being of own sex ${ }^{a}$} \\
\hline Girls & 66.8 & 28.2 & 3.5 & 0.7 & 0.5 & 0.2 \\
\hline Boys & 86.7 & 9.4 & 2.5 & 0.6 & 0.6 & 0.9 \\
\hline \multicolumn{7}{|c|}{ Felt uncertain about own gender } \\
\hline Girls & 0.7 & 1.0 & 3.2 & 8.2 & 86.5 & 0.2 \\
\hline Boys & 2.2 & 0.9 & 2.5 & 3.5 & 90.6 & 0.3 \\
\hline \multicolumn{7}{|c|}{ Felt pressured by others to be a girl/boy } \\
\hline Girls & 0.2 & 0.7 & 2.7 & 7.7 & 87.5 & 1.0 \\
\hline Boys & 0.9 & 0.6 & 2.2 & 2.2 & 92.5 & 1.6 \\
\hline \multicolumn{7}{|c|}{ Felt has to work at being a girl/boy } \\
\hline Girls & 0.2 & 0.5 & 5.0 & 12.5 & 81.3 & 0.5 \\
\hline Boys & 0.9 & 2.2 & 1.3 & 2.5 & 92.6 & 0.6 \\
\hline \multicolumn{7}{|c|}{ Felt was not a real girl/boy } \\
\hline Girls & 1.0 & 0.3 & 1.0 & 2.8 & 94.8 & 0.2 \\
\hline Boys & 1.9 & 0.6 & 1.3 & 1.3 & 94.7 & 0.3 \\
\hline \multicolumn{7}{|c|}{ Felt that it would be better to live as the opposite sex } \\
\hline Girls & - & 3.0 & 9.7 & 15.7 & 71.6 & 0.2 \\
\hline Boys & 1.3 & 1.3 & 2.2 & 6.9 & 88.1 & 0.3 \\
\hline \multicolumn{7}{|c|}{ Had dreams, was of the opposite sex in them } \\
\hline Girls & 0.2 & 0.2 & 3.5 & 7.2 & 82.5 & 6.2 \\
\hline Boys & 1.3 & 0.6 & 3.1 & 2.2 & 76.7 & 16.0 \\
\hline \multicolumn{7}{|c|}{ Unhappy about being a girl/boy } \\
\hline Girls & 0.2 & 0.5 & 5.0 & 16.5 & 77.6 & 0.2 \\
\hline Boys & 0.6 & 0.9 & 2.2 & 2.2 & 92.8 & 0.6 \\
\hline \multicolumn{7}{|c|}{ Uncertain about oneself, at times feeling more like opposite sex and at times more like own sex } \\
\hline Girls & - & 1.7 & 4.5 & 9.5 & 84.0 & 0.2 \\
\hline Boys & 0.6 & 0.9 & 1.9 & 3.8 & 92.1 & 0.6 \\
\hline \multicolumn{7}{|c|}{ Felt more like of the opposite sex } \\
\hline Girls & 0.2 & 0.5 & 3.2 & 7.2 & 88.8 & - \\
\hline Boys & 0.6 & 0.9 & 0.9 & 1.3 & 95.6 & 0.6 \\
\hline \multicolumn{7}{|c|}{ Felt not anything in common with either boys/girls } \\
\hline Girls & - & 1.7 & 5.3 & 13.7 & 76.1 & 3.2 \\
\hline Boys & 1.6 & 1.3 & 2.8 & 10.1 & 79.6 & 4.7 \\
\hline Bothered by se & identified & & & & & \\
\hline Girls & 1.5 & 0.5 & 1.2 & 1.0 & 96.8 & 3.2 \\
\hline Boys & 2.8 & 0.6 & 0.6 & 0.9 & 95.0 & - \\
\hline Felt comfortabl & /boys' rest & & & & & \\
\hline Girls & 91.2 & 1.3 & 0.5 & 0.8 & 6.2 & 0.7 \\
\hline Boys & 84.6 & 2.5 & 1.3 & 1.3 & 10.4 & - \\
\hline Treated as of th & ex by stral & & & & & \\
\hline Girls & 0.2 & 0.7 & 2.2 & 6.2 & 90.3 & 0.2 \\
\hline Boys & 0.9 & 0.3 & 1.6 & 3.1 & 93.4 & 0.6 \\
\hline Treated by frieı & as of the & & & & & \\
\hline Girls & 0.2 & 0.7 & 2.2 & 6.2 & 90.3 & 0.2 \\
\hline Boys & 0.9 & 0.3 & 0.9 & 2.8 & 94.7 & 0.3 \\
\hline Wish or desire & osite sex & & & & & \\
\hline Girls & - & 0.7 & 8.5 & 22.4 & 68.3 & - \\
\hline Boys & 0.6 & 0.9 & 0.6 & 6.9 & 90.9 & - \\
\hline Dressed and ac & ite sex & & & & & \\
\hline Girls & 0.5 & 2.7 & 8.7 & 17.2 & 70.6 & 0.2 \\
\hline Boys & 1.3 & 0.6 & 1.6 & 6.0 & 89.9 & 0.6 \\
\hline Presented as a & at parties & ial gathe & & & & \\
\hline Girls & - & 0.2 & 0.7 & 1.7 & 97.3 & - \\
\hline Boys & 0.3 & 1.3 & - & 1.3 & 97.2 & - \\
\hline Presented as of & t work or & & & & & \\
\hline Girls & - & - & 0.7 & 2.5 & 96.3 & 0.5 \\
\hline Boys & 1.3 & 0.3 & 0.3 & 1.3 & 96.9 & - \\
\hline Disliked own b & it was fem & & & & & \\
\hline Girls & 0.5 & 0.7 & 2.5 & 5.0 & 90.5 & 0.7 \\
\hline Boys & 0.6 & 0.9 & 1.9 & 2.5 & 93.4 & 0.6 \\
\hline Wished to have & eatment $\mathrm{t}$ & body to & opposite sex & & & \\
\hline Girls & - & - & 0.5 & 2.0 & 97.3 & 0.2 \\
\hline Boys & 1.9 & 0.3 & 0.9 & 0.6 & 96.2 & - \\
\hline Wished to have & $\mathrm{n}$ to chang & dy to th & osite sex & & & \\
\hline Girls & - & - & 0.7 & 0.5 & 99.5 & 0.5 \\
\hline Boys & 1.3 & 0.6 & 0.9 & 0.9 & 96.2 & - \\
\hline Has made an ef & ge legal se & & & & & \\
\hline Girls & - & - & - & 0.2 & 99.5 & 0.2 \\
\hline Boys & 0.9 & 1.6 & 0.3 & 0.3 & 96.9 & - \\
\hline
\end{tabular}


Table 1 (continued)

\begin{tabular}{|c|c|c|c|c|c|c|}
\hline GIDYQ-A item & Always & Often & Some-times & Rarely & Never & Missing \\
\hline \multicolumn{7}{|c|}{ Thought of oneself as hermafrodite/intersex } \\
\hline Girls & - & 0.5 & 1.7 & 2.7 & 93.0 & 2.0 \\
\hline Boys & 0.6 & 0.6 & 0.6 & 1.9 & 95.9 & 0.3 \\
\hline \multicolumn{7}{|c|}{ Thought of oneself as transgendered person } \\
\hline Girls & - & 0.2 & 0.5 & 1.5 & 97.3 & 0.5 \\
\hline Boys & 1.3 & 0.6 & 0.3 & 1.9 & 95.9 & - \\
\hline \multicolumn{7}{|c|}{ Thought of oneself as a being of opposite sex } \\
\hline Girls & - & 0.7 & 1.7 & 3.5 & 93.8 & 0.2 \\
\hline Boys & 0.9 & 0.6 & 0.6 & 1.3 & 96.5 & - \\
\hline \multicolumn{7}{|c|}{ Thought of oneself as a being of own sex ${ }^{a}$} \\
\hline Girls & 90.8 & 6.0 & 0.5 & 0.7 & 1.5 & 0.5 \\
\hline Boys & 92.1 & 2.5 & - & 1.3 & 3.8 & 0.3 \\
\hline
\end{tabular}

Note. Median score was 1 in all items marked with ${ }^{\mathrm{a}}$, and 5 in all other items, similarly among both girls and boys.

a Item was reverse coded when calculating total sum score.

\section{Table 2}

Means (standard deviations) and interquartile ranges (IQR) of the four subscales of the Recalled Childhood Gender Identity among community sample girls and boys and among FtM and MtF sex reassignment applicants. The subscale means are compared between community girls and boys, community girls and FtM applicants and community boys and MtF applicants using independent samples $t$-test.

\begin{tabular}{|c|c|c|c|c|c|c|c|}
\hline RGCI-subscale where & $\begin{array}{l}\text { Community } \\
\text { girls }(n=401)\end{array}$ & $\begin{array}{l}\text { Community } \\
\text { boys }(n=318)\end{array}$ & $\begin{array}{l}\text { FtM } \\
\text { applicants } \\
(n=41)\end{array}$ & $\begin{array}{l}\text { MtF } \\
\text { applicants } \\
(n=6)\end{array}$ & $\begin{array}{l}p^{\text {a }} \text {, community } \\
\text { sample, girls vs. } \\
\text { boys }\end{array}$ & $\begin{array}{l}p^{\mathrm{a}}, \text { community girls } \\
\text { vs. FtM applicants }\end{array}$ & $\begin{array}{l}p^{\mathrm{a}} \text {, community boys } \\
\text { vs. MtF applicants }\end{array}$ \\
\hline $\begin{array}{l}\text { Higher value is assumed } \\
\text { female-typical }\end{array}$ & $24.3(5.2)$ & $10.3(3.0)$ & $13.4(4.4)$ & $15.0(6.8)$ & $<0.001$ & $<0.001$ & $<0.001$ \\
\hline IQR & $21.0-28.0$ & $8.0-12.0$ & $10.3-15.8$ & $7.8-19.8$ & & & \\
\hline $\begin{array}{l}\text { Higher value is assumed } \\
\text { male typical }\end{array}$ & $7.1(2.5)$ & $12.4(2.5)$ & $11.2(3.0)$ & $9.2(4.2)$ & $<0.001$ & $<0.001$ & 0.002 \\
\hline IQR & $5.0-9.0$ & $10.0-15.0$ & $9.0-14.10$ & $4.8-13.3$ & & & \\
\hline $\begin{array}{l}\text { Lower value reflects greater } \\
\text { gender conformity }\end{array}$ & $13.8(3.1)$ & $11.8(3.0)$ & $15.6(4.2)$ & $16.0(6.1)$ & $<0.001$ & 0.010 & 0.001 \\
\hline IQR & $12.0-16.0$ & $10.0-13.0$ & $14.0-18.8$ & $8.8-20.8$ & & & \\
\hline $\begin{array}{l}\text { Lower value reflects greater } \\
\text { gender nonconformity }\end{array}$ & $13.5(2.1)$ & $14.4(1.9)$ & $10.8(3.2)$ & $11.7(4.5)$ & $<0.001$ & $<0.001$ & 0.001 \\
\hline $\mathrm{IQR}$ & $13.0-15.0$ & $15.0-15.0$ & $8.0-13.8$ & $6.5-15.0$ & & & \\
\hline
\end{tabular}

a $t$-test; p-values highlighted in bold were statistically significant after Bonferroni correction.

validated gender identity measures widely used in European and North American gender assessment clinics, do not explore identity processes. The approaches used in identity development research at large should be integrated into gender identity research. A limitation is that GIDY-A and RCGI have not been validated in community youth. The strength of this study was the unselected upper secondary school population. Another limitation was that we did not include same-aged students in vocational schools, or collect sociodemographic data other than age. Upper secondary school attendance predicts higher socioeconomic status than attending vocational school. Transgender identity may be associated with a higher level of education (Factor \& Rothblum, 2007), possibly suggesting higher than average gender variance in our sample. As adolescents rather accentuate than downplay belonging to minorities (Robinson-Cimpian, 2014), the prevalence figures obtained for possibly clinical gender dysphoria may be overestimated. Further, transgender youth present with more mental health and psychosocial problems than average (Clark et al., 2014; Connolly et al., 2016) and it is a limitation that we did not have information on the community youth's health. Despite these limitations, main study results indicated that community youth mainly reported normative, conforming gender experiences. Adolescent population gender identity polarizes at the cis- and transgender ends of the scale with little variation in between. Our findings strengthen earlier estimates that about $1 \%$ of adolescents present with gender dysphoria/variation. Understanding epidemiology in this area is important for resource allocation in services.

\section{Funding}

This work was supported by Pirkanmaa Hospital District [Research Grant 9R014].

\section{Appendix A. Supplementary data}

Supplementary data related to this article can be found at http://dx.doi.org/10.1016/j.adolescence.2017.01.006 


\section{References}

Aitken, M., Steensma, T. D., Blanchard, R., Van der Laan, D. P., Wood, H., Fuentes, A., et al. (2015). Evidence for an altered sex ratio in clinic-referred adolescents with gender dysphoria. Journal of Sexual Medicine, 12, 756-763. http://dx.doi.org/10.1111/jsm.12817.

American Psychiatric Association. (2013). Diagnostic and statistical manual of mental disorders (5th ed.). Washington DC: Author.

Arcelus, J., Bouman, W. P., Van Den Noortgate, W., Claes, L., Witcomb, G., \& Fernandez-Aranda, F. (2015). Systematic review and meta-analysis of prevalence studies in transsexualism. European Psychiatry, 30, 807-815. http://dx.doi.org/10.1016/j.eurpsy.2015.04.005.

Clark, T. C., Lucassen, M. F. G., Bullen, P., Denny, S. J., Fleming, T. M., Robinson, E. M., et al. (2014). The health and well-being of transgender high school students: Results from the New Zealand Adolescent Health Survey (Youth'12). Journal of Adolescent Health, 55, 93-99.

Connolly, M. D., Zervos, M. J., Barone, C. J., Johnson, C. C., \& Joseph, C. L. M. (2016). The mental health of transgender youth: Advances in understanding. Journal of Adolescent Health. http://dx.doi.org/10.1016/j.jadohealth.2016.06.012 [Epub ahead of print].

Costa, R., Carmichael, P., \& Colizzi, M. (2016). To treat or not to treat: Puberty suppression in childhood-onset gender dysphoria. Nature Reviews Urology, 13, 456-462.

Deogracias, J., Johnson, L., Meyer-Bahlburg, H., Kessler, S., Schober, J., \& Zucker, K. (2007). The gender identity/gender dysphoria questionnaire for adolescents and adults. Journal of Sex Research, 44, 370-379.

Diemer, E. W., Grant, J. D., Munn-Chernoff, M. A., Patterson, D. A., \& Duncan, A. E. (2015). .Gender identity, sexual orientation, and eating-related pathology in a national sample of college students. Journal of Adolescent Health, 57, 144-149.

Eige (n.d.). retrieved from http://eige.europa.eu/content/publications.

Factor, R. J., \& Rothblum, E. D. (2007). A study of transgender adults and their non-transgender siblings on demographic characteristics, social support, and experiences of violence. Journal of Lgbt Health Research, 3, 11-30.

Kaltiala-Heino, R., Sumia, M., Työläjärvi, M., \& Lindberg, N. (2015). Two years of gender identity service for minors: Overrepresentation of natal girls with severe problems in adolescent development. Child \& Adolescent Psychiatry \& Mental Health, 9(9). http://dx.doi.org/10.1186/s13034-015-0042-y.

Kroger, J., Martinussen, M., \& Marcia, J. E. (2010). Identity status change during adolescence and young adulthood: A meta-analysis. Journal of Adolescence, 33, 683-698. http://dx.doi.org/10.1016/j.adolescence.2009.11.002.

Kuyper, L., \& Wijsen, C. (2014). Gender identities and gender dysphoria in The Netherlands. Archives of Sexual Behaviour, 43, 377-385. http://dx.doi.org/10. 1007/s10508-013-0140-y.

Luyckx, K., Teppers, E., Klimstra, T. A., \& Rassart, J. (2014). Identity processes and personality traits and types in adolescence: Directionality of effects and developmental trajectories. Developmental Psychology, 50, 2144-2153. http://dx.doi.org/10.1037/a0037256.

Meyenburg, B. (2014). Geschlechtsdysphorie im Jugendalter Schwierige Behandllungsverlaufe [Gender dysphoria in adolescents: Difficulties intreatment] Praxis Der Kinderpsychologie Und Kinderpsychiatrie, 63, 510-522.

Meyenburg, B., Korte, A., Moller, B., Romer, G., \& Deutsche Gesellschaft für Kinder- und Jugendpsychiatrie, Psychosomatik und Psychotherapie. (2014). Störungen der Geschlechtsidentität im Kindes- und Jugendalter (F64) [Gender identity disorders in childhood and adolescence (F64)] Praxis Der Kinderpsychologie Und Kinderpsychiatrie, 63, 542-552.

Moshman, D. (2011). Adolescent rationality and development. Cognition, morality, and identity (3rd ed.). New York: Psychology Press.

Olson-Kennedy, J., Cohen-Kettenis, P. T., Kreukels, B. P. C., Meyer-Bahlburg, H. F. L., Garofalo, R., Meyer, W., et al. (2016). Research priorities for gender nonconforming/transgender youth: Gender identity development and biopsychosocial outcomes. Current Opinion in Endocrinology, $23,172-179$.

Ristori, J., \& Steensma, T. D. (2016). Gender dysphoria in childhood. International Review of Psychiatry, 28, 13-20.

Robinson-Cimpian, J. R. (2014). Inaccurate estimation of disparities due to mischievous responders: Several suggestions to assess conclusions. Educational Researcher, 43, 171-185.

Tilastokeskus. (2016). Naiset ja miehet Suomessa 2016. Retrieved from http://www.stat.fi/tup/tasaarvo/julkaisut.html.

Wood, H., Sasaki, S., Bradley, S. J., Singh, D., Fantus, S., Owen-Anderson, A., et al. (2013). Patterns of referral to a gender identity service for children and adolescents (1976-2011): Age, sex ratio, and sexual orientation. Journal of Sex \& Marital Therapy, 39, 1-6. http://dx.doi.org/10.1080/0092623X.2012. 675022 .

World Health Organization. (1992). The ICD-10 classification of mental and behavioural disorders: Clinical descriptions and diagnostic guidelines. Geneva: Author.

Zucker, K., Mitchell, J., Bradley, S., Tkachuk, J., Cantor, J., \& Allin, S. (2006). The recalled childhood gender identity/gender role questionnaire: Psychometric properties. Sex Roles, 54, 469-483. http://dx.doi.org/10.1007/s-11199-006-9019-x. 